\title{
Prooxidative Role of Hyperinsulinemia in Metabolic Sydrome Formation
}

\author{
Nelli Uzbekova', Dilorom Musakhodjaeva ${ }^{2}$ \\ ${ }^{1}$ Andijan State Medical Institute Andijan, Uzbekistan \\ ${ }^{2}$ Immunomorphology DPT, Institute of Immunology, Academy of Science, Uzbekistan
}

\begin{tabular}{|c|c|}
\hline Article Info & ABSTRACT \\
\hline Article history: & The pattern of hyperinsulinemia was studied in patients with metabolic \\
\hline Received Jun 4, 2013 & $\begin{array}{l}\text { syndrome. The levels of basal insulinemia (BI), malondialdehyde (MDA) } \\
\text { and catalaze (CA) as an index of oxidative stress and some metabolic }\end{array}$ \\
\hline Revised Jan 20, 2014 & parameters have been studied in men and women with metabolic syndrome. \\
\hline Accepted April 26, 2014 & \\
\hline \multicolumn{2}{|l|}{ Keyword: } \\
\hline \multicolumn{2}{|l|}{ Insulinemia } \\
\hline \multicolumn{2}{|l|}{ Malondialdehyde } \\
\hline \multicolumn{2}{|l|}{ Catalaze } \\
\hline \multicolumn{2}{|l|}{ Metabolic parameters } \\
\hline Metabolic syndrome & $\begin{array}{r}\text { Copyright (C) } 2014 \text { Institute of Advanced Engineering and Science. } \\
\text { All rights reserved. }\end{array}$ \\
\hline \multicolumn{2}{|l|}{ Corresponding Author: } \\
\hline \multicolumn{2}{|c|}{$\begin{array}{l}\text { Dilorom Musakhodjaeva, } \\
\text { Immunomorphology DPT, Institute of Immunology, } \\
\text { Uzbekistan Academy of Science, } \\
74 \text { Yahyo Gulyamov, Tashkent 100060, Uzbekistan. } \\
\text { Email: dilym@xnet.uz, ranosabitova@yahoo.com }\end{array}$} \\
\hline
\end{tabular}

\section{INTRODUCTION}

Currently, a metabolic syndrome (MS) is becoming the one of the most important and growing health issues in Uzbekistan. The presence of MS is associated with increased risk of coronary artery disease and atherothrombosis [1].

There are very important mechanisms in the course of oxidative stress (OS) connected with the process of atherothrombosis, especially in cardiovascular version of MS. The major components of the OS are "respiratory burst" in polymorphonuclear leukocytes, lipoprotein peroxidation (LPO) and the antioxidant enzymes. They lead to endothelial dysfunction, which triggers a cascade of reactions involved in the formation of atherosclerotic plaques [2].

Activators of these processes are various specific and nonspecific factors. Among them, a special place has a hyperinsulinemia (HI) - the main pathogenetic mechanism for the MS development [2],[3]. In assessing its participation in the OS we have to remember that the complex relationships of insulin with other metabolic factors are not fully detected yet. Possible pathophysiological relationships of insulinemia with gender differences, age factor and the speed of developing of atherosclerotic vascular changes may play an important role [2]-[4].

Levels of malondialdehyde (MDA), the system of functionally interrelated antioxidant enzymes, including catalase (CA), are considered as sensitive index of the OS, and accordingly, of an increased lipid peroxidation and increased atherogenecity [1],[2],[5].

The purpose of this study was to analyze the interrelationships between basal insulinemia and parameters of malondialdehyde and catalase, and influence of metabolic components of metabolic syndrome on these processes. 


\section{RESEARCH METHOD}

A group of 40 men (mean age 52,4 $\pm 0,7$ years) and 35 women (mean age 49,5 $\pm 0,8$ years) with a diagnosis of MS were examined. Mean levels of systolic and diastolic blood pressure in both groups were $154,05 \pm 2,62 / 99,34 \pm 1,43$ and 150,21 $\pm 3,12 / 88,28 \pm 2,18 \mathrm{~mm} \mathrm{Hg}$. Anthropometric parameters of patients - a body mass index (BMI), waist circumference (WC ) and metabolic - total cholesterol (TC), triglycerides (TG), low density lipoproteins (LDL), high-density lipoprotein (HDL) cholesterol, blood glucose and basal insulin ( BI) - are reflected in Figure 1, 2,3. The control group consisted of 10 healthy men and 10 healthy women with normal blood pressure $(116,17 \pm 1,32$ / 74,32 $\pm 1,27 \mathrm{~mm} \mathrm{Hg})$. Insulin levels were determined by ELISA automated method using ELISA kits of «Accubind Microwells» firm (USA) in the laboratory "Immunogen-Test" at the Institute of Immunology of Uzbekistan Academy of Science (Tashkent). Lipid levels were measured by the biochemical analyzer express «Reflotron Plus» (Roche, Germany). LDL was calculated by Friedwald. The content of lipid peroxidation was assessed by the level in the blood serum of the secondary product - MDA determined by reaction with 2-thiobarbituric acid. Catalase activity was determined from the pressure oxidation molybdate with hydrogen peroxide. Statistical analysis of the results was conducted in the statistical softwire "Statistica".

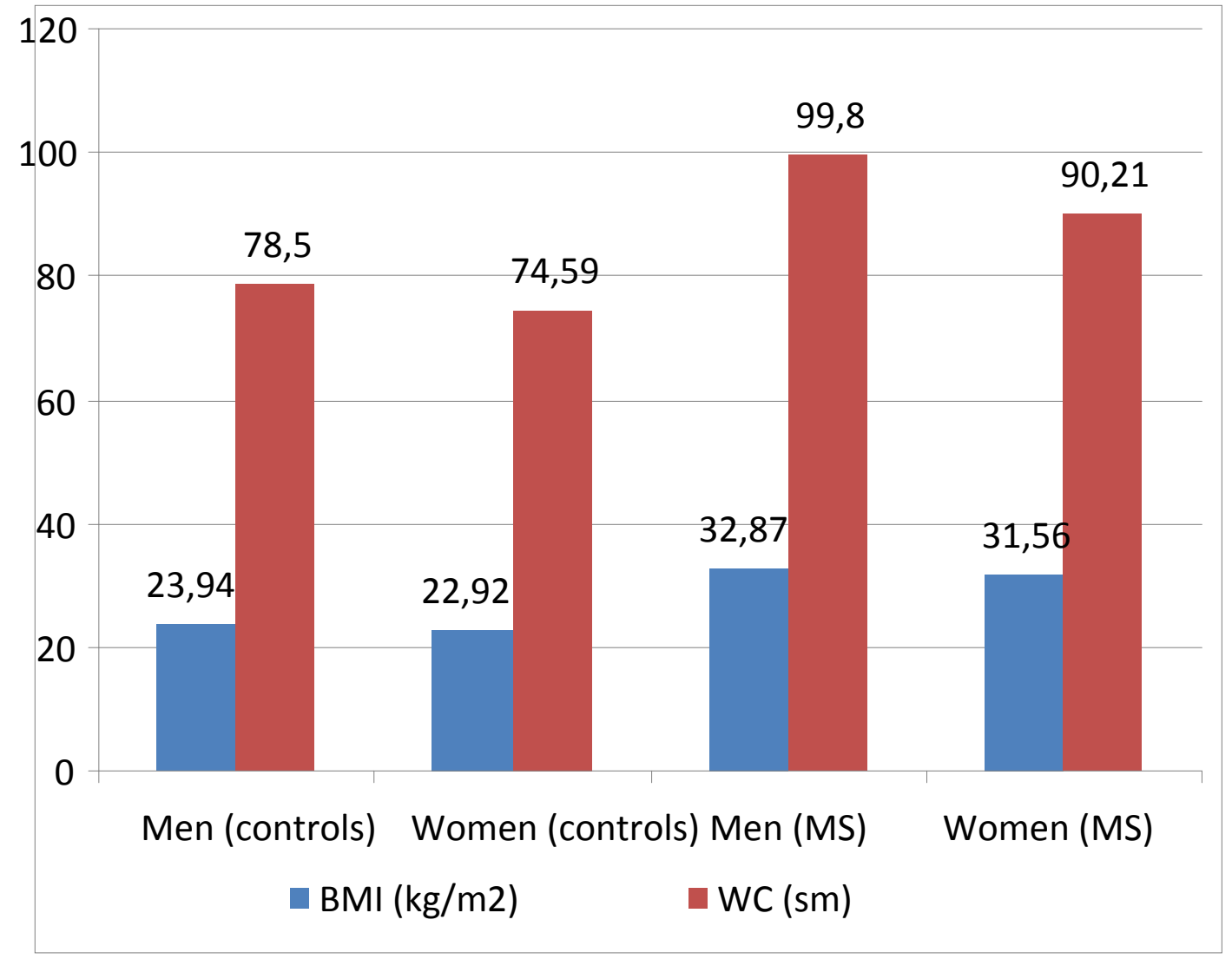

Figure 1 Clinical parameters of patients with metabolic syndrom

\section{RESULTS AND ANALYSIS}

In determining of $\mathrm{BI}$ in men with MS levels $(22,8 \pm 0,57 \mathrm{mU} / \mathrm{L})$ were higher then control values $(10,14 \pm 0,39 \mathrm{mU} / \mathrm{L})$, and it was almost twice higher, confirming a presence of hyperinsulinemia. When comparing BI women with MS $(15,05 \pm 0,61 \mathrm{mU} / \mathrm{ml})$ and in the control group $(10,07 \pm 0,63 \mathrm{mU} / \mathrm{L})$ less increase of its level. Significant difference in levels of BI based on gender justifies need in the further study of the insulinemia linkages with other components of MS, the parameters of which a group of men and women are different (Figure 2). 


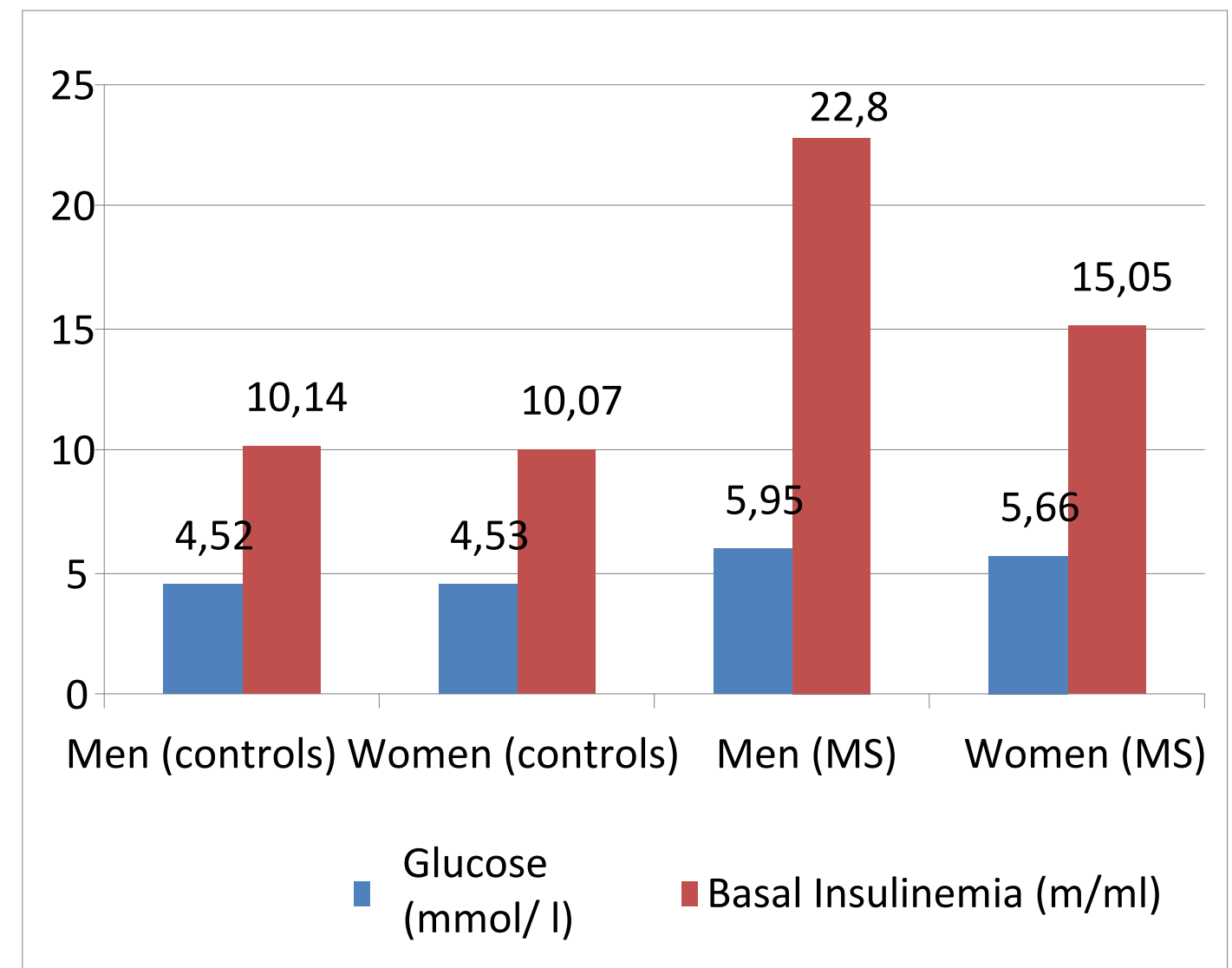

Figure 2 Glucose-insulin characteristics of patients with metabolic syndrome

Thus, in men compared to women on the background of similar systolic blood presure, there was a significant $(\mathrm{p}<0.001)$ higher levels of diastolic blood pressure $(99,34 \pm 1,43$ and 88,28 $\pm 2,18 \mathrm{~mm} \mathrm{Hg}$, respectively) with greater duration of hypertension $(9,55 \pm 0,84$ and 3,25 $\pm 0,29$ years). At comparable several metabolic (BMI, blood glucose, high cholesterol) parameters of men and women differed significantly in the degree of deposition of abdominal adipose tissue $(p<0.001)$, triglycerides $(p<0.001)$ and LDL $(\mathrm{p}<0.001)$ (Figure 3$)$. 


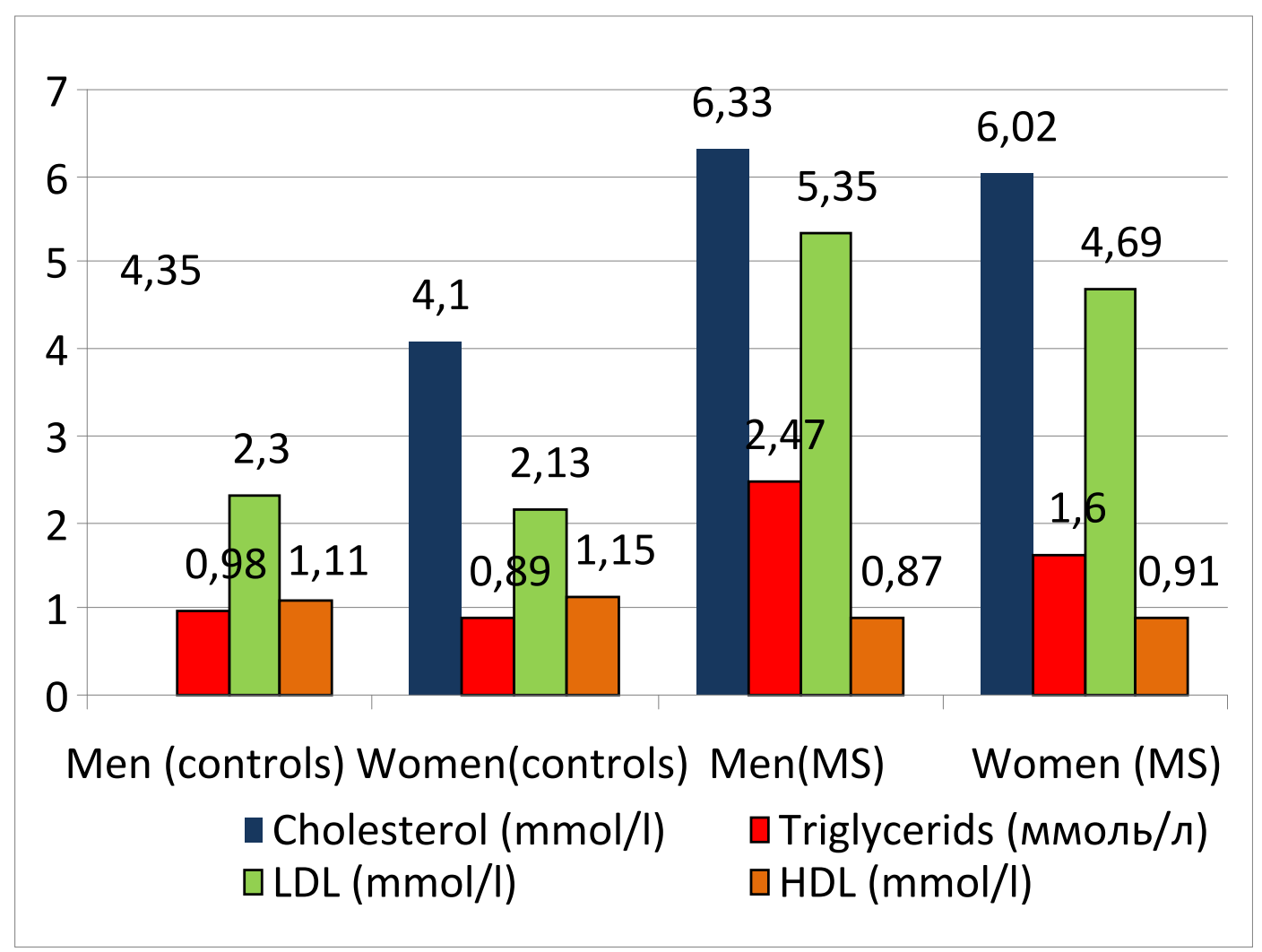

Figure 3 Lipid profile in patients with metabolic syndrome

Correlation analysis BI levels with parameters of body weight in men with metabolic syndrome revealed reliable direct correlation. Regression analysis of the relationship with BMI levels of insulinemia showed that the influence of anthropometric parameters on the functional state of the $\beta$-cells becomes significant at a BMI $\geq 28 \mathrm{~kg} / \mathrm{m} 2(\mathrm{p}=0,32, \mathrm{p}=0.03)$. At the same time insulinemia provided significant influence on BMI levels in BI from $15.0 \mathrm{mU} / \mathrm{ml}$ and higher $(\mathrm{p}=0,34, \mathrm{p}=0.047)$. Regression last depending showed that the value of $\mathrm{r}$ reaches 0.54 at moderate $\mathrm{GI}(\geq 18,0 \mathrm{mU} / \mathrm{ml})$ in contrast to 0.37 in considering as independent variables BMI. This suggests a greater importance of the GI in the relationship with BMI [2],[6].

Analysis of the relationship of BI had shown that RT at $100 \mathrm{~cm}$ and has a stable significant stimulating effect on insulinemia (maximum $p=0,54, p=0.003$ ). At the same time, help to increase the levels of BI and WC, starting with $13.5 \mathrm{mU} / \mathrm{L}$ (maximum $\mathrm{p}=0,66, \mathrm{p}=0.004$ ).

In women with MS, only WC was correlated with the level BI $(p=0,40, p=0.02)$. The regression analysis, therefore, did not find its credible depending on the specific parameter values of insulinemia and WC. In men, levels of MS BI at a value of $13 \mathrm{mU} / \mathrm{ml}$, and more directly correlated with $\mathrm{TG}(\mathrm{P}=0,29, \mathrm{p}=$ 0.046). At higher BI $(\geq 17 \mathrm{mU} / \mathrm{ml})$ significantly negative correlation with $\operatorname{HDL}(\mathrm{p}=-0,36, \mathrm{p}=0.049)$ and insulinemia was not correlated with lipid parameters.

MDA concentrations in males exceeded 2-fold then target MS $(p<0.01)$. In women with MS and without, the levels of MDA were not different (Figure 4). However, the correlation of MDA with insulin was significant $(p<0.01)$ both in men $(p=0,35)$, and in women $(p=0,50)$. In men, this association became significant in the GI ( $\geq 16 \mathrm{mU} / \mathrm{L})$, and in women it does not depend on the specific values of BI. MDA levels in men and correlated with the ratio of $\mathrm{WC}$ and $\mathrm{ON}(\mathrm{p}=0,43, \mathrm{p}<0.05)$ in the absence of this connection in women.

Catalase levels in MS worsened rapidly, and in men it was more pronounced than women (p $<0.001)$. Marked inverse correlation with the level of SC insulin in both men $(p=-0,34)$, and in women $(p=-$ $0,32)$. Also in the GI $(\geq 0,15 \mathrm{mU} / \mathrm{L})$, this feedback becomes more important. SC concentration was inversely correlated with RT in both men $(p=-0,34)$, and in women $(p=-0,32)$.

The BI level in men was treated as GI. GI in women was less pronounced. The effect of gender on the components of MS, sold through the environmental factors previously reported Poulsen P. et al. (2001) 
and Perova N. et al. (2011) [2],[7]. Layer BI floor, some authors explain differences in lifestyle, including eating patterns [4],[8].

Significant differences in levels of BI in men and women interested in the MS in terms of features insulinemia correlations with other components of the cluster [2],[4]. In our study, insulin correlated with the parameters by which these groups differed - RT, TG, LDL. The nature of the identified correlations also depend on gender.

The men in the regression analysis identified the key role in the relationship BI with anthropometric parameters. In considering the nature of the relationship of abdominal obesity and GI [1],[2], these data support the primacy of its in men. Closer significant correlations with BI $(p=0,66)$ compared with BMI $(p=$ $0,34)$ in men and a relationship BI with $\mathrm{WC}$ in women $(\mathrm{P}=0,40, \mathrm{p}=0.02)$. It indicates a value of abdominal obesity (AO) as a clinical marker of MS. For women in perimenopause BI correlated only with WC. The existence of these correlations is consistent with the conclusion of D. Corry on the role of visceral fat accumulation in women as a constant SG at the same time lower values of postprandial insulin, which is particularly important in light of the possible presence of MI in men without AD.

It is associated with AS typical MS indicators dyslipoproteinemia (DLP): TG, decreased HDL [1],[4],[9]. It is therefore logical appearance in men correlations with parameters BI DLP in this order: the levels of insulinemia $12 \mathrm{mU} / \mathrm{L}$ or more is significant $(\mathrm{p}<0.05)$, its relationship with TG $(\mathrm{P}=0,29)$ in the BI $17 \mathrm{mU} / \mathrm{ml}$ or more - feedback with parameters $\operatorname{HDL}(\mathrm{P}=-0,34)$.

Gender differences of characteristics of lipid metabolism and lack of correlation with BI female MC may be associated with different levels of insulinemia [2]. However, in healthy young women had higher rates and lower HDL - TG compared to men with similar levels of BI [6],[10]. Gender differences of basal and postprandial insulinemia and TG explain certain differences in the accumulation of visceral fat in men and women [3][6]. Strongest possible association with other components of the GI of MS in women have when they have type 2 diabetes [4].

The differences in the levels and correlation link BI with anthropometric and lipid parameters reflect the different role of insulin in the mechanisms of formation of metabolic syndrome in men and women. This defines the different approaches to the diagnosis of GI and R \& D based on gender. If men surrogate, but a valid marker of this state is BI, then women should be assessed insulinemia in stress tests [2],[7]. In postmenopausal women, revealed a closer relationship between the lipid characteristics and GI [6]. At the same time, the universality of the correlations with BI FROM proves the value of this simple measurement in the diagnosis of MS.

In associations with metabolic BI components of MS in men and women are interesting in terms of their relationship with the mechanisms of the operating system. There is evidence of more pronounced OS in men [6],[9],[10]]. There is a report about the protective role of estradiol in the protection of the vessel wall in response to the OS [10], in addition to traditional ideas about its effects on lipid metabolism.

These data are consistent that we identified: higher levels of MDA $(p<0.001)$ and low levels of CA in men MS ( $p<0.001)$ in contrast to healthy men and women. Due to the generally accepted role of MDA and spacecraft, as indicators of the oxidative stress [2],[8] is of interest to them based on gender. Some attempts have been made to assess the relationship of oxidized LDL with the parameters AO, closely related to the DLP and IR / GI [5],[9]. In this connection it is informative indicators revealed the relationship of MDA and the spacecraft with BI and WC. When significant differences in the levels of BI, MDA and CA in men and women of the correlation of the same type, which may reflect the value of prooxidant insulinemia regardless of gender. The prooxidant role of $\mathrm{BI}$ in men is becoming a significant ( $\mathrm{P}=0,35, \mathrm{p}<0.05$ only in GI conditions.

Insulinemia affect OS options in two ways in male patients - directly (correlation with MDA), back (correlation with SC) and indirectly through the characteristics of a more pronounced their AO (BI correlation with RT and RT with MDA, CA). At the same time, the presence of correlation relationship of BI women in the absence of GI can argue the importance they even low levels of insulin in the formation of the MS-clinical marker of abdominal obesity. These data are consistent with the view that an important pathophysiological role of R \& D and GM in the induction mechanisms of AO [1],[5],[8].

\section{CONCLUSION}

Thus, the assumption is that the realization of gender differences in the intensity of the operating system happens through hormonal factors under the influence of age and insulinemia. Possible mechanisms of insulinemia's prooxidant role in MS are modulated by AO parameters according to gender. The presence of gender differences of the insulin action to the endothelium explains closer connection of GI and cardiovascular diseases in men, unlike women. 


\section{REFERENCES}

[1] Ametov A., Belykh A., "Efficiency correction $\neg$ violations of carbohydrate and lipid metabolism in patients with high risk factors" $\neg$ "E [Effektivnost korrektsii narusheniy uglevodnogo i lipidnogo obmena u lic s visokimi factorami riska]", Rus. medical Journal [Russkiy Medicinskiy Jurnal], vol/issue: 15(28), pp. 2156, 2007.

[2] Perova N., Ozerov I., Aleksandrovich O., et al, "The clinical significance of insulin resistance in fasting normoglycemia" "[Klinicheskoe znachenie insulinorezistentnosti pri normoglikemii natoshak]", Cardiology [Kardiologia], issue: 8, pp. 49-53, 2011.

[3] Kumagai S., Kai Y., Sasaki H., "Relationship between insulin resistance, gender hormones and gender hormonebinding globulin in the serum lipid and lipoprotein profiles of Japanese postmenopausal women", J. Arterioscier. Thromb, vol. 8, pp. 14-20, 2001..

[4] Wirfalt E., Hedblad B., Gullberg B., et al., „Food patterns and components of the metabolic Malmo Diet and Cancer cohort”, Am. J. Epidemiol., vol. 154, pp. 1150-1159, 2001.

[5] Maturana M., Spritzer P., "Association between hyperinsulinemia and androgen levels in peri- and postmenopausal women”, Metabolism, vol. 51, pp. 238-243, 2002.

[6] Corry D., "Gender-related differences in the insulinresistance syndrome", Curr. Hypertens. Rep, issue: 3, pp. 124$128,2001$.

[7] Poulsen P., Vang A., Kyvik K., et al., « Genetic versus environmental etiology of the metabolic syndrome among male and female twins", Diabetologia, vol. 44, pp. 537-543, 2001.

[8] Polidori M., Cherubini A., Stahl W., et al., 'Plasma carotenoid and malondialdehyde levels in ischemic stroke patients: relationship to early outcome”, Free Radic. Res, vol. 36, pp. 265-268, 2002.

[9] Fano G., Mecocci P., Vecchiet J., el al., "Age and gender influence on oxidative damage and functional status in guman skeletal muscle", J. Muscle Res, vol. 22, pp. 345-351, 2001.

[10] Dimirrova K., DeGroot K., Myers A., et al., «Estrogen and homocysteine”, Cardiovasc. Res, vol. 53, pp. 577$588,2002$.

\section{BIOGRAPHIES OF AUTHORS}

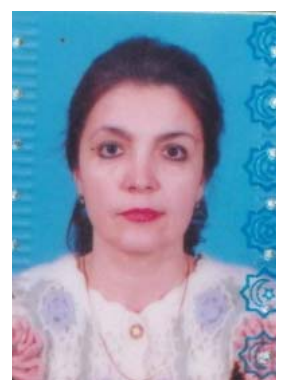

Nelli Uzbekova, MD.

Works at the Andijan State Medical Institute, the cardiology department, her scientific ineterests are in fundamental and applied immunology, currently she is working on $\mathrm{PhD}$ dissertation topic devoted to non-communicable diseases.

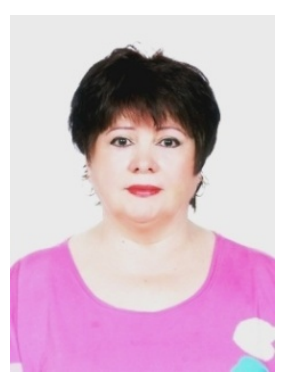

Dilorom Musakhodjaeva, Doctor of Biological Science is the Chief of the Immunomorphology DPT of the Institute of Immunology, Uzbekistan's Academy of Science. Her scientific interests are in the fundamental and applied immunology, immunophisiology, immune mechanisms of inflammation, developing tumors and ophalmic diseases, endocrinology, reproductive and pediatric immunology as well.

Phone: +998 712330113 (of)

e-mail: dilym@xnet.uz 